\title{
Dietary diversification/modification strategies to enhance micronutrient content and bioavailability of diets in developing countries
}

\author{
Rosalind S. Gibson* and Christine Hotz \\ Department of Human Nutrition, University of Otago, Dunedin, New Zealand
}

\begin{abstract}
Both cereal staples and household diets can be manipulated to enhance the content of micronutrients and/or alter the levels of absorption modifiers to improve micronutrient bioavailability. Strategies described range from plant breeding, use of fertilizers and genetic engineering to changes in food preparation and processing methods at the household level involving soaking, fermentation and germination. The impact of five household strategies designed to enhance the content and bioavailability of iron, zinc and calcium in a representative daily menu for rural Malawian preschool children has been calculated using food composition data. In the five strategies, relishes based on small dried fish replaced plant-based relishes, maize-based porridges prepared with maize flour soaked to reduce its hexa (IP-6)- and penta (IP-5)-inositol phosphate content replaced conventional porridges; and a pumpkin-leaf relish replaced sweet potato to increase the retinol content of the daily menu. Comparison of the calculated energy, nutrient, and phytate content, and [phytate]:[zinc] molar ratios of the five modified menus compared with the unmodified menu emphasizes that to ensure that the estimated requirements for iron and zinc are met, the optimal strategy includes dried fish relish twice daily together with porridges prepared using soaked (or fermented) maize flour to reduce their hexa- and penta-inositol phosphate content. Implementation of these household strategies has the potential to increase the bioavailability of iron and zinc in rural Malawian diets from low to high.
\end{abstract}

Dietary strategies: Micronutrient content: Bioavailability: Developing countries: Plantbased staples

\section{Introduction}

In 1990, the World Health Organization (WHO), United Nations Children's Fund (UNICEF), and the World Summit for Children endorsed the elimination of micronutrient malnutrition in developing countries by the year 2000, specifically deficiencies of vitamin A, and two trace elements - iodine and iron. At that time, deficiencies of these micronutrients were estimated to affect the health, mental and physical function, and survival of more than two billion people worldwide. In the Third Report of the World Nutrition Situation (United Nations ACC/SCN, 1997), a third trace element, zinc, was added to this list.

Deficiencies of these micronutrients arise from inadequate intakes, impaired absorption and/or utilization, excessive losses, or a combination of these factors and are exacerbated during times of greater physiological need such as infancy, pregnancy, lactation and catch-up growth following illness. In many developing countries, rural diets are based predominantly on cereals and legumes or starchy roots and tubers: consumption of flesh foods such as meat, poultry, and small whole fish with bones, readily available sources of iron, zinc, and preformed vitamin A, is often small because of economic, cultural and religious constraints. In general, diets based on starchy roots and tubers have a lower micronutrient content than those based on unrefined cereals and legumes. However, the latter often contain high levels of phytic acid (myo-inositol hexaphosphate) and polyphenols which inhibit zinc and/or nonhaem iron absorption by forming insoluble complexes in the intestine. Consequently, the bioavailability of micronutrients in diets based on cereals and legumes is often poor (Gibson, 1994).

Nutrition intervention strategies to reduce the occurrence of micronutrient malnutrition include: supplementation, fortification and dietary diversification/modification. This review focuses on dietary diversification/modification, an approach that aims to enhance the availability, access, and utilization of foods with a high content and bioavailability of micronutrients throughout the year. It involves changes in food production practices, food selection patterns, and traditional household methods for preparing and processing indigenous foods. To implement these strategies effectively, knowledge of the local dietary patterns, and food beliefs, preferences and taboos is required, as well as the ability to change attitudes and practices. Dietary 
Table 1. Phytate content $(\mathrm{mg} / 100 \mathrm{~g})$ of cereal grains: whole grain, milled, and genetically modified

\begin{tabular}{lcc}
\hline & $\begin{array}{c}\text { Phytate } \\
\text { (mg/100 g) }\end{array}$ & Source \\
\hline Maize flour, white, 95 \% extraction (Zea mays L.) & 792 & Ferguson et al. (1988) \\
Maize flour, white, 65\% extraction & 211 & Ferguson et al. (1988) \\
Maize, yellow, wild-type & 988 & Mendoza et al. (1998) \\
Maize, yellow, low-phytic acid 1-1 & 348 & Mendoza et al. (1998) \\
Rice, white, milled (Oryza sativa) & 350 & Bunch \& Murphy,(1997) \\
Rice, brown, milled (Oryza sativa) & 838 & Bunch \& Murphy (1997) \\
Rice, low-phytic acid 1-1 & 143 & Raboy (pers. comm.) \\
Wheat flour, whole grain (Triticum aestivum) & 845 & Bunch \& Murphy (1997) \\
Wheat flour, 85 \% extraction & 564 & Bunch \& Murphy (1997) \\
Wheat flour, 70\% extraction & 282 & Bunch \& Murphy (1997) \\
Millet, finger, dry (Eleusine coracana) & 520 & Bunch \& Murphy (1997) \\
Sorghum, dry (Sorghum bicolor [L.] Moench) & 439 & Bunch \& Murphy (1997) \\
Cowpea, dry (Vigna unguiculata [L.] Walp.) & 945 & Bunch \& Murphy (1997) \\
Groundnut, dry (Arachis hypoganea L.) & 1760 & Bunch \& Murphy (1997) \\
Soybean, dry (Glycine max) & 691 & Bunch \& Murphy (1997) \\
\hline
\end{tabular}

diversification/modification may be more sustainable, economically feasible, and culturally acceptable than supplementation or fortification and can be used to alleviate several micronutrient deficiencies simultaneously without risk of antagonistic interactions (Gibson \& Ferguson, 1998).

\section{Strategies to enhance the content and/or bioavailability of micronutrients in plant-based staples}

Until recently, horticultural and agricultural programs, in combination with social marketing, have been used primarily for combating vitamin A deficiency (de Pee et al. 1998). There is now increasing interest in developing high yielding genotypes of indigenous wild plants resistant to drought and heat, which are rich sources of iron and zinc as well as provitamin A carotenoids (Becker, 1986; Kim \& Oh, 1996; Malaisse \& Parent, 1985), because they are easily cultivated and accepted by local rural communities (Shrimpton, 1995).

Field fortification strategies can also be used to increase the content of certain trace elements (TE) in cereal grains by applying fertilizers to the soil to increase its content of selenium, iodine, and zinc, or to the leaves to enhance their iron content. Alternatively, plant-breeding can be employed to produce new varieties of cereal grains, orange-fleshed sweet potatoes and cassava roots, with an increased content of iron, zinc, and/or beta-carotene (Iglesias, 1996; Hagenimana et al. 1999), or genotypes in which the TE are remobilized from the vegetative parts to the grain (Graham $\&$ Welch, 1996). Modern genetic alterations are being used to modify cereals such as rice (Oryza sativa) to contain beta-carotene (Ye et al. 2000) and increase their content of iron through the use of a ferritin transgene from Phaseolus vulgare (Portrykus et al. Personal communication). All these approaches have the potential to have a major impact on the micronutrient intakes of population groups who derive at least $50 \%$ of their dietary energy from a single cereal staple, such as maize, rice, or cassava.

Plant breeding, genetic mutations, and genetic engineering strategies are also being developed to improve the bioavailability of micronutrients in cereal staples by altering their content of absorption modifiers. For some cereals (e.g. maize), plant breeding may be used to enhance their content of methionine and cysteine, sulfur-containing amino acids which promote zinc and non-haem iron absorption (House et al. 1996). Selection of mutants and genetic engineering can also be used to reduce the content of absorption inhibitors (e.g. phytate), and increase the content of mineral absorption enhancers. For example, a gene which codes for a sulphur-rich metallothionein-like protein can be introduced into rice (Oryza sativa), a protein which increases the resorption-enhancing effect of iron from the small intestine.

Genetic mutations can be used to reduce the content of mineral absorption inhibitors, such as phytate, which naturally occurs in abundance in cereals (Table 1). For example, induced genetic mutations which block the synthesis of phytate in corn, barley and rice, can reduce the level of phytic acid phosphorus by more than $50 \%$ in these cereals (Raboy et al. 1989). A low-phytate maize prepared by this method was assessed for absorption of iron from tortillas using the extrinsic labeling technique (Mendoza et al. 1998). The phytic acid content of the maize was reduced by about one third of that of the parent, wild-type strain (Table 1). Iron absorption was $49 \%$ greater from tortillas prepared from the low-phytate maize (8.2 \% of intake) compared to those from the wild-typestrain $(5.5 \%$ of intake $)(P<0.001)$.

Another approach to reducing the inhibiting effects of phytate on mineral absorption is by introducing genes for phytase enzyme into cereals. Phytase enzymes (myoinositol hexaphosphate phosphohydrolases) hydrolyze phytic acid (myo-inositol hexaphosphate) to yield myo-inositol and inorganic phosphate via intermediate myo-inositol phosphates: inositol mono-, bi-, tri-, tetra-, and pentaphosphates (IP-1, IP-2, IP-3, IP-4, and IP-5 respectively; Irving, 1980). When myo-inositol phosphates have less than five phosphate groups (i.e. IP-4 to IP-1), they do not have a negative effect on zinc absorption (Lönnerdal et al. 1989). However, for iron, the myo-inositol phosphates must contain less than three phosphate groups before iron absorption is no longer inhibited in processed foods (Sandberg et al. 1999). Genes for phytase have been 
Table 2. Menus for 4-6-year-old Malawian children incorporating five strategies to enhance their nutrient content and bioavailability

Daily menu Breakfast: $257 \mathrm{~g}$ unrefined maize porridge, $196 \mathrm{~g}$ boiled sweet potato

Lunch: $279 \mathrm{~g}$ unrefined maize nsima, $88 \mathrm{~g}$ pumpkin leaf relish

Evening meal: $279 \mathrm{~g}$ unrefined maize nsima, $111 \mathrm{~g}$ pigeon-pea relish, $43 \mathrm{~g}$ roast groundnuts

Strategy $1 \quad$ Breakfast: $257 \mathrm{~g}$ unrefined maize porridge, $196 \mathrm{~g}$ boiled sweet potato

Lunch: $279 \mathrm{~g}$ unrefined maize nsima, $100 \mathrm{~g}$ dried fish relish

Evening meal: $279 \mathrm{~g}$ unrefined maize nsima, $100 \mathrm{~g}$ small dried fish relish, $43 \mathrm{~g}$ roast groundnuts

Strategy 2 Breakfast: $257 \mathrm{~g}$ unrefined maize porridge, $88 \mathrm{~g}$ pumpkin leaf relish

Lunch: $279 \mathrm{~g}$ unrefined maize nsima, $100 \mathrm{~g}$ small dried whole fish (with bones) relish

Evening meal: $279 \mathrm{~g}$ unrefined maize nsima, $100 \mathrm{~g}$ small dried whole fish (with bones) relish, $43 \mathrm{~g}$ roast groundnuts

Strategy $3 \quad$ Breakfast: $257 \mathrm{~g}$ soaked unrefined maize porridge, $196 \mathrm{~g}$ boiled sweet potato

Lunch: $279 \mathrm{~g}$ soaked unrefined maize nsima, $100 \mathrm{~g}$ small dried whole fish (with bones) relish

Evening meal: $279 \mathrm{~g}$ soaked unrefined maize nsima, $100 \mathrm{~g}$ small dried whole fish (with bones) relish, $43 \mathrm{~g}$ roast groundnuts

Strategy $4 \quad$ Breakfast: $257 \mathrm{~g}$ soaked unrefined maize porridge, $88 \mathrm{~g}$ pumpkin leaf relish

Lunch: $279 \mathrm{~g}$ soaked unrefined maize nsima, $100 \mathrm{~g}$ small dried whole fish (with bones) relish

Evening meal: $279 \mathrm{~g}$ soaked unrefined maize nsima, $100 \mathrm{~g}$ small dried whole fish (with bones) relish, $43 \mathrm{~g}$ roast groundnuts

Strategy $5 \quad$ Breakfast: $257 \mathrm{~g}$ soaked unrefined maize porridge, $196 \mathrm{~g}$ boiled sweet potato

Lunch: $279 \mathrm{~g}$ soaked unrefined maize nsima, $88 \mathrm{~g}$ pumpkin leaf relish

Evening meal: $279 \mathrm{~g}$ soaked unrefined maize nsima, $111 \mathrm{~g}$ pigeon pea relish, $43 \mathrm{~g}$ roast groundnuts

transferred from Aspergillus niger into tobacco seeds (Pen et al. 1993), and a transgene for a heat stable phytase from Aspergillus fumigatus has been incorporated into rice.

For cereals in which phytic acid is localized in the outer aleurone layer (e.g. rice, sorghum and wheat) or in the germ (i.e. maize), milling can be used to reduce their phytic acid content (Table 1) (O’Dell et al. 1972), although the mineral content may also be simultaneously reduced. Careful milling can also reduce the dietary fibre content which may enhance iron and zinc absorption to some degree. Removal of the testa in legumes does not remove their phytic acid content because it is distributed within the cotyledons (Gibson \& Ferguson, 1998).

\section{Strategies to enhance the content and bioavailability of micronutrients in household diets}

Some practical dietary strategies exist for enhancing the content and bioavailability of micronutrients in household plant-based diets consumed in developing countries and they are outlined below. Some of these strategies do not involve substantial changes in the quantity of flesh foods consumed, and hence are particularly appropriate in countries where socio-economic conditions and religious beliefs make the promotion of flesh food consumption impractical.

To illustrate the impact of the proposed strategies on both the amount and bioavailability of micronutrients, five modifications to a representative daily menu for a female Malawian child aged 4-6 years of age are shown in Table 2 (i.e. strategies 1-5). For the representative menu and for each strategy, the daily intakes of energy, protein, carbohydrate, fat, vitamin $\mathrm{A}$, niacin, folate, vitamin $\mathrm{B}_{12}$, phytate [Phy], dietary fibre (as non-starch polysaccharide), and [Phy]:[Zn] and [Phy]:[Fe] molar ratios have been calculated using our Malawian food composition data (Ferguson, 1992) and some values from the World Food Dietary Assessment System (Bunch \& Murphy, 1997). These modified nutrient and antinutrient intakes have been compared with the unmodified intakes and the corresponding estimated nutrient requirements, taking into account any potential changes in the bioavailability of the iron and zinc achieved in the modified menus (Table 3). Such changes have been assessed by using algorithms developed by the Food and Agricultural Organization/World Health Organization (FAO/WHO, 1988) for iron and the World Health Organization (WHO, 1996) for zinc. Values for the estimated nutrient requirements are taken from the United Kingdom Dietary Reference Values (DRV) (COMA, 1991), as used by WHO (1998), with the exception of zinc, iron, retinol, folate and vitamin $\mathrm{B}_{12}$. For zinc, the basal and normative requirement estimates published by the World Health Organization (WHO, 1996) have been used. For iron, retinol, folate and vitamin $\mathrm{B}_{12}$, the levels proposed by FAO/WHO (1988) were applied, using the basal requirement estimates for iron and retinol, and the safe levels of intake for folate and vitamin $B_{12}$. Note that deficits in the energy, calcium, iron, zinc, and vitamin $B_{12}$ exist in the representative menu when compared to the energy and estimated nutrient requirements shown in Table 3 , when low bioavailability for iron and zinc are assumed.

Incorporation of flesh foods such as dried whole fish with bones to enhance micronutrient content and bioavailability in the daily diet

Incorporation of some flesh foods into predominantly plant-based diets in developing countries has many advantages. Flesh foods are good sources of readily available haem iron and zinc, as well as vitamin $B_{12}$, riboflavin, and in some cases, preformed vitamin $\mathrm{A}$, and additional micronutrients frequently limiting in plant-based diets. They also enhance the absorption of non-haem iron and zinc from plant-based foods, even in the presence of dietary inhibitors such as phytic acid (Cook \& Monsen, 1976; Sandström et al. 1989). The relative enhancing effect of animal muscle proteins on non-haem iron absorption varies: beef apparently has the highest at about $220 \%$, 
Table 3. Energy, selected nutrient and antinutrient content and [Phy]:[Fe] and [Phy]:[Zn] molar ratios of daily menus (Table 2) compared to nutrient requirements

\begin{tabular}{|c|c|c|c|c|c|c|c|c|c|c|c|c|c|c|c|}
\hline & $\mathrm{kJ}$ & $\begin{array}{l}\text { Prot } \\
\text { (g) }\end{array}$ & $\begin{array}{l}\text { Fat } \\
\text { (g) }\end{array}$ & $\begin{array}{c}\mathrm{CHO} \\
(\mathrm{g})\end{array}$ & $\begin{array}{l}\text { NSP } \\
(\mathrm{g})\end{array}$ & $\begin{array}{c}\mathrm{Ca} \\
(\mathrm{mg})\end{array}$ & $\begin{array}{l}\mathrm{Fe} \\
(\mathrm{mg})\end{array}$ & $\begin{array}{l}\mathrm{Zn} \\
(\mathrm{mg})\end{array}$ & $\begin{array}{l}\text { Vit A } \\
(\mathrm{RE})\end{array}$ & $\begin{array}{l}\text { Folate } \\
\text { (ug) }\end{array}$ & $\begin{array}{l}\text { VitB12 } \\
\text { (mg) }\end{array}$ & $\begin{array}{l}\text { Niacin } \\
(\mathrm{mg})\end{array}$ & $\begin{array}{l}\text { Phy } \\
\text { (mg) }\end{array}$ & $\begin{array}{c}{[\mathrm{Phy}]} \\
:[\mathrm{Fe}]\end{array}$ & $\begin{array}{c}{[\mathrm{Phy}]} \\
:[\mathrm{Zn}]\end{array}$ \\
\hline Daily Menu & 6586 & 46.9 & 32.5 & 251 & $31 \cdot 8$ & 190 & $12 \cdot 1$ & $7 \cdot 2$ & 218 & 232 & 0 & $15 \cdot 3$ & 2168 & $15 \cdot 2$ & 30.0 \\
\hline Strategy 1 & 6158 & $58 \cdot 6$ & 39.6 & 227 & 24.7 & 811 & $13 \cdot 8$ & $18 \cdot 2$ & 48 & 163 & $5 \cdot 8$ & $15 \cdot 1$ & 1890 & 11.6 & $10 \cdot 3$ \\
\hline Strategy 2 & 5791 & $58 \cdot 9$ & 39.9 & 174 & $22 \cdot 2$ & 842 & $12 \cdot 9$ & $18 \cdot 3$ & 252 & 188 & $5 \cdot 8$ & 15.9 & 1902 & 12.5 & $10 \cdot 3$ \\
\hline Strategy 3 & 6158 & 58.6 & 39.6 & 227 & 24.7 & 811 & $13 \cdot 8$ & $18 \cdot 2$ & 48 & 163 & $5 \cdot 8$ & $15 \cdot 1$ & 826 & $5 \cdot 1$ & 4.5 \\
\hline Strategy 4 & 5791 & 58.9 & 39.9 & 174 & $22 \cdot 2$ & 842 & $12 \cdot 9$ & $18 \cdot 3$ & 252 & 188 & $5 \cdot 8$ & $15 \cdot 9$ & 838 & 5.5 & 4.5 \\
\hline Strategy 5 & 6586 & $46 \cdot 9$ & 32.5 & 251 & $31 \cdot 8$ & 190 & $12 \cdot 1$ & $7 \cdot 2$ & 218 & 232 & 0 & $15 \cdot 3$ & 1104 & $7 \cdot 8$ & $15 \cdot 3$ \\
\hline \multirow[t]{2}{*}{$\mathrm{RNI}$} & 6460 & $19 \cdot 7$ & & & & 450 & $7.0 \mathrm{~B}$ & $6 \cdot 5 \mathrm{~N} \ddagger$ & $200 B \S$ & $62^{\star \star}$ & $0.75^{\prime \prime}$ & 11.01 & & & \\
\hline & & & & & & & $\dagger$ & $3.9 \mathrm{E}$ & & & & & & & \\
\hline
\end{tabular}

kJ, energy in kilojoules; Prot, protein; CHO, carbohydrate; NSP, non-starch polysaccharide; Phy, phytate; [Phy]:[Fe], molar ratio of phytate:iron; [Phy]:[Zn], molar ratio of phytate:zinc; $\mathrm{RNI}$, estimated nutrient requirement plus a safety factor of $2 \mathrm{SD}$; $\mathrm{N}$, normative requirement; $\mathrm{B}$, basal requirement.

* Estimated average requirement for energy for females. Taken from COMA (1991).

† Basal requirement including variability and assuming $10 \%$ bioavailability. For low bioavailability diets assuming $5 \%$ absorption, basal requirement including variability is $14 \mathrm{mg}$; for high bioavailability (i.e.15\%), basal requirement including variability is $5 \mathrm{mg}$ for children $2-5$ years and 8 mg for children $6-12$ years. From FAO/WHO (1988).

† Requirement assuming $35 \%$ bioavailability for basal and $30 \%$ for normative. Based on WHO (1996). For low bioavailability diets (i.e. 15\%) absorption, basal and normative requirement estimates are $9.2 \mathrm{mg} /$ day and $12.9 \mathrm{mg} /$ day respectively. For high bioavailability diets (i.e. $55 \%$ absorption for basal), basal requirement estimate is $2.5 \mathrm{mg} /$ day. The normative requirement assuming $50 \%$ absorption is $3.9 \mathrm{mg} / \mathrm{day}$. From WHO (1996).

$\S$ Basal requirement including variability. Taken from $\mathrm{FAO} / \mathrm{WHO}(1988)$

// From COMA (1991).

In Safe level of intake (3.3 ug/kg/day) taken from FAO/WHO (1988) and the median weight of 5-year-old boy (18.7 kg) based on WHO (1983).

** Safe level of intake $(0.04 \mathrm{ug} / \mathrm{kg} /$ day) taken from FAO/WHO (1988) and the median weight of 5-year-old boy (18.7 kg) based on WHO (1983).

lamb, pork, liver, chicken about $140 \%$ and fish about $75 \%$ (Cook \& Monsen, 1976; Lynch et al. 1989). To our knowledge, no comparable data exist for zinc.

In many countries, fish is a more feasible alternative than meat or poultry, especially in countries where economic, religious and/or cultural factors prevent the consumption of meat and poultry. Fish contains moderate levels of readily available haem iron; approximately $60 \%$ of the iron in fish is highly bioavailable haem iron. Fish is also a relatively good source of fat, riboflavin, niacin, vitamin $\mathrm{B}_{12}$, calcium and readily available zinc, provided it is consumed whole with bones; fish flesh without bones is much lower in calcium and zinc (Holland et al. 1993; Maage \& Julshamn, 1993). Some species of fatty fish (e.g. mackerel) are also a good source of preformed vitamin A.

Small dried whole fish eaten with bones have been selected for strategy 1 because they are more readily available and consumed more often than meat or poultry in rural Malawi (Huddle, 1996), and are often available for consumption in developing countries (Table 2). When prepared as a fish flour, they can be used to enrich cerealbased porridges used for infant and child feeding. Table 3 depicts the corresponding nutrient changes to the representative Malawian menu when the plant-based relishes are substituted by $100 \mathrm{~g}$ of fish relish twice daily, each serving containing $24 \mathrm{~g}$ of small dried fish (Usipa), consumed whole with bones. Note that this substitution has resulted in a $152 \%$ increase in zinc intake but only a $14 \%$ increase in daily iron intake. Marked increases in intakes of vitamin $\mathrm{B}_{12}$ and calcium (327\%), and to a lesser extent fat (22\%) have also occurred when compared to intakes in the unmodified daily menu (Table 3). Further, calcium absorption from small soft-boned fish eaten whole with the bones appears to be comparable to that of milk (Hansen et al. 1998). By contrast, at the same time, decreases in the phytate intake (12\%), [Phy]:[Fe] (15.2 v. 11.6) and
[Phy]:[Zn] (30.0 v. 10.3) molar ratios are apparent. Such reductions, in combination with a source of cellular animal protein such as dried fish, have the potential to increase the bioavailability of both non-haem iron and zinc from low to moderate (FAO/WHO, 1988; WHO, 1996). Note that the vitamin A content of this modified menu has been dramatically reduced. However, this deficit can be rectified by using fatty fish, substituting boiled sweet potato with a variety with a higher carotenoid content (Hagenimana et al. 1999), or using a relish of pumpkin leaves, as shown in strategy 2 . The marked increase in vitamin $B_{12}$ intake is also noteworthy in view of the recent findings from the Nutrition CRSP study which highlighted the high prevalence of vitamin $\mathrm{B}_{12}$ deficiency in Mexican preschool and school aged children, as well as women. The low plasma $\mathrm{B}_{12}$ concentrations were accompanied by low red blood cell counts and, in some cases, a tendency to macrocytosis; plasma folate values were not low (Allen, 1994).

\section{Use of soaking to enhance micronutrient bioavailability in household diets for infant and child feeding}

Despite the inclusion of two servings of dried fish relish in the adjusted menu described, and the consequent reduction in the [Phy]:[Zn] molar ratio, the bioavailability of iron and zinc in this menu is still only moderate. Hence, strategy 1 has been further modified to reduce the IP-5 and IP-6 content of the unrefined maize-based staples (i.e. porridge and stiff-maize based porridge called nsima) by incorporating unrefined maize flour that has been soaked prior to use (strategy 3). Soaking reduces the IP-5 and IP-6 content of unrefined maize (and most legumes) via passive diffusion because their phytic acid is stored in a relatively water-soluble form such as sodium and potassium phytate (De Boland et al. 1975; Chang et al. 1977). Further, 
soaking may also activate endogenous cereal phytases (myo-inositol hexaphosphate phosphohydrolases (EC $3 \cdot 1 \cdot 3 \cdot 26$ ), the level of their activity depending on the species and variety, temperature and $\mathrm{pH}$ (Bartnik \& Szafranska, 1987). Room temperature $\left(50^{\circ} \mathrm{C}\right)$ is optimal for phytases in maize (Zea mays L. (Gram)) as well as white sorghum (Sorghum bicolour (1). Moench (Gram)) and soybeans (Glycine max), whereas for wheat (Triticum aestivum) and several varieties of beans such as mung beans (Phaseolus aureus) and lima beans (P. lunatus), temperatures of about $60^{\circ} \mathrm{C}$ are optimal. The optimum $\mathrm{pH}$ for phytase activity ranges from 4.0 to 7.5 , with corn (Zea mays) having a $\mathrm{pH}$ optimum of $5 \cdot 6$, rice (Oryza sativa) $\mathrm{pH} 4 \cdot 2$, and black beans (Phaseolus vulgaris var. preto) pH 6.0 (Lasztity \& Lasztity, 1990; Greiner \& Konietzny, 1999).

In strategy 3, the value for IP-5 and IP-6 content of soaked unrefined maize flour used to calculate the phytate content of the soaked maize-based porridges is derived from our laboratory analyses. It is equivalent to a $38 \%$ reduction in IP-5 and IP-6 content of the unrefined Malawian maize flour analyzed in our laboratory and used for strategy 1 . The impact of these changes on nutrient and antinutrient content of the menu is also shown in Table 3 . Note that as a result of the increase in readily available haem iron and zinc derived from the small dried fish with bones, combined with the dramatic reduction in the [Phy]:[Zn] (30 v. 4) and [Phy]:[Fe] (15 v. 5) molar ratios as a consequence of the soaking, there will probably be a shift from low to high bioavailability for zinc (i.e. from 15 to $50 \%)(\mathrm{WHO}, 1996)$ and possibly for iron (i.e. from 5 to $15 \%)$ (FAO/WHO, 1988). Hence, the FAO/WHO (1988) and WHO (1996) basal requirements for iron and the normative requirements for zinc are likely to be met, as well as the reference nutrient intake for calcium (COMA, 1991). Again the vitamin A content of this menu is also below the FAO/WHO (1988) level, but can be rectified by the substitution of sweet potato by pumpkin leaf relish, as shown in the menu depicted in strategy 4.

Finally, in strategy 5 , the fish relish has been omitted but the porridge and nsima have been prepared with soaked unrefined maize flour to illustrate the impact of reducing the phytate content alone on the nutrient adequacy of the representative daily menu. Despite the expected reductions in the phytate content and molar ratios of [Phy]:[Zn] and $[\mathrm{Phy}]:[\mathrm{Fe}]$, the bioavailability of non-haem iron and zinc is unlikely to be increased from low to moderate in this menu that incorporates soaking alone; the [Phy]:[Zn] molar ratio is still above 15 (i.e. 15.3), and the level of phytate is still high (i.e. $1104 \mathrm{mg}$ ). Reducing the phytate content of a maize-based diet is known to have very little impact on iron absorption, unlike zinc, unless the final phytate content is extremely low (Allen \& Ahluwalia, 1997). These results emphasize the importance of including a source of cellular animal protein in combination with a reduction in the phytate content in order to improve the bioavailability of iron and zinc in maize-based diets. Consumption of ascorbic acid-rich foods such as citrus fruits with the main meals is also an additional strategy that can be used to further enhance non-haem iron absorption (Hallberg \& Rossander, 1984).
Use of fermentation to enhance micronutrient bioavailability in household diets for infant and child feeding

Reductions in IP-5 and IP-6 levels can also be achieved by phytase-induced hydrolysis of phytate during fermentation. Microbial phytases act over a broader $\mathrm{pH}$ range (i.e. 2.5$5.5)$ than cereal phytases $(4 \cdot 5-5.6)$, and at the physiological conditions of the stomach (Sandberg, 1991). By optimizing the conditions for fermentation, the phytic acid content of cereal-based porridges can sometimes be reduced by as much as $90 \%$ (Svanberg et al. 1993). Fermentation also improves the protein quality and digestibility, vitamin B content, microbiological safety and keeping quality, while at the same time enhancing the iron and zinc bioavailability. Nevertheless, the amount of phytate reduction and subsequent increase in the bioavailabilty of iron and/or zinc induced by fermentation has not yet been studied systematically using a range of fermentation techniques and cereal cultivars.

Alternatively, commercial phytase enzymes prepared from Aspergillus oxyzae, A. niger, or A. fumigatus that facilitate phytate hydrolysis over an even longer fermentation period because they are stable over a broader $\mathrm{pH}$ range (3.5-7.8) and for A. fumigatus, wider temperature range, can be used. Sandberg et al. (1996), using radioactive isotopes, recently reported increased iron absorption (i.e. 26.1 v. $14.3 \%$ ) in individuals fed with single meals containing white wheat rolls supplemented with phytasedeactivated wheat bran but with added microbial phytase from $A$. niger compared to those receiving the same meal but with no added microbial phytase. The high cost of these commercially produced microbial phytases, however, probably precludes their use in many developing countries at the present time.

To date, in vivo studies of iron and zinc bioavailability in cereal porridges prepared with and without soaking or fermenting flour slurries are limited, although some in vitro measurements of soluble iron have been reported (Svanberg et al. 1993). Animal studies have shown greater femoral zinc in rats fed with diets containing fermented soybean meal than those fed with regular soyabean meal, probably resulting from increased zinc solubility in the small intestine (Hirabayashi et al. 1998).

\section{Use of germinated cereals to enhance micronutrient density and bioavailability in porridges for infant and child feeding}

Germinated flours can be used to enhance the energy and nutrient density of cereal-based porridges for infant feeding, while simultaneously reducing their phytate content to some degree (Table 3). When added (at the level of 5-10\%) to thick cereal-based porridges (i.e. 20$28 \%$ dry matter), their viscosity is reduced to an easy-toswallow semi-liquid consistency suitable for infant and child feeding (i.e. from $50000 \mathrm{cP}$ to $3000 \mathrm{cP}$ ) without dilution with water (Mosha \& Svanberg, 1990). This is achieved by hydrolysis of amylase and amlyopectin to dextrins and maltose induced by alpha-amylase (EC $3 \cdot 2 \cdot 1 \cdot 1$ ), which increases during germination. Some reduction in IP-5 and IP-6 may occur because germination also 
increases phytase activity as a result of de novo synthesis or activation of endogenous phytase (myo-inositol hexaphosphate phosphohydrolases (EC 3·1·3.26) (Lorenz, 1980; Bartnik \& Szafranska, 1987). Germination also reduces the content of polyphenols and tannins in some legumes (e.g. Vicia faba) (Camacho et al. 1992).

\section{Practical recommendations to facilitate implementation of household strategies}

Some practical recommendations are provided to facilitate implementation of the strategies discussed above; they are summarized below.

(1) Promote plant breeding strategies for improving the micronutrient content and bioavailability of selected plant-based staples. These strategies are especially appropriate for use in populations who derive at least $50 \%$ of their dietary energy from a single food crop. However, for plant breeding to become a viable strategy, farmers must be assured that the new cultivars have no agronomic disadvantages, consumers must be educated to purchase them, and scientists must confirm their efficacy and effectiveness in terms of enhancing micronutrient status of the consumers.

(2) Promote small livestock production in local communities, where possible. Examples include production of rabbits, cavies, guinea pigs and poultry as well as ruminants. Intake of such flesh foods is most frequently constrained by cost. Household consumption of small livestock must be actively encouraged to ensure that they are not sold for cash, and/or not regarded only as 'special' foods (e.g. guinea-pigs in highland Ecuador), although care must be taken to avoid potential hazards of transfer of zoonotic infections such as Campylobacter infections and Salmonella from poultry, Cryptosporidium from pigs (Mølbak et al. 1997).

(3) Install refrigeration in community shops or in conjunction with village mills. Limited access to household refrigeration and in local community-based shops may be an important factor limiting the consumption of flesh foods. Therefore, provision of refrigeration facilities could be encouraged in appropriate settings to encourage the purchase and/or consumption of flesh foods in rural communities.

(4) Encourage integration of aquaculture into farming systems, and encourage village-based technologies for drying fish and preparing fish flour. Small softboned fish consumed with bones are important sources of readily available zinc, calcium, iron, vitamin $\mathrm{B}_{12}$, and for some species, preformed vitamin A, especially in countries where religious and/or cultural factors prevent the consumption of meat and poultry. Small dried fish consumed as a whole are a practical alternative because they do not require refrigeration. When prepared as fish flour, they can be used to enrich cereal-based porridges for infants, children, pregnant and lactating women, although care must be taken to avoid rancidity. Use of a new farmer-focused systems approach whereby aquaculture is incorporated into existing farming systems with the minimum of investment should be explored to enhance the contribution of aquaculture in household nutrition (Brummett \& Haight, 1996).

(5) Target flesh foods to household members at high risk for iron and zinc inadequacies. Infants, pre-schoolers, and pregnant and lactating women have high micronutrient requirements. Therefore, certain nutrient dense foods should be preferentially allocated to those with higher nutrient needs, and the practice of eating from a common pot be discouraged. As well, nutrition education must be undertaken to stress the special nutritional needs of these high risk groups.

(6) Promote consumption of maize-based staples prepared from soaked or fermented unrefined maize flours. These can be prepared from pounded maize or maize flour which has been soaked before use. Alternatively, fermented slurries and doughs using unrefined cereal flours can be used, provided the sour flavour of the fermented products is acceptable. Such strategies will reduce the [Phy]:[Zn] and [Phy]:[Fe] molar ratios and hence enhance zinc, and possibly non-haem iron bioavailability. Additional advantages of consuming fermented products should also be emphasized, as discussed earlier.

(7) Enrich cereal-based porridges with legume flours, as well as fruits and vegetables rich in ascorbic acid and provitamin A carotenoids. Legume flours should be soaked before being used to enrich porridges to reduce their phytic acid content. The addition of ascorbic acid-rich foods can counteract the inhibitory effects of phytic acid and polyphenols on non-haem iron absorption, provided they are consumed at the same meal.

(8) Encourage addition of amylase-rich flours to cerealbased porridges used for infant feeding. This practice can reduce the viscosity of thick porridges to semiliquid consistency suitable for infant feeding, without adding extra water, thus enhancing their energy and nutrient density. Care must be taken during the preparation of germinated cereals (i.e. malted grains), especially when sorghum is used, to ensure that after germination, the roots and shoots are removed-termed 'devegetated', before the germinated grains are dried, and ground into flour. The germinated flour should be thoroughly dried before storage to avoid growth of molds such as aflatoxin.

\section{Conclusions}

Strategies do exist to improve the content and bioavailability of micronutrients in plant-based staples as well as diets used in developing countries. Such strategies range from genetic engineering of staple foods and increased production of animal source foods to those based at the household level such as soaking, fermentation and germination. Calculation of the energy, nutrient and antinutrient intakes derived from incorporating five possible strategies into a representative menu for rural Malawian 
preschoolers has revealed that reduction of the hexa- and penta-inositol phosphate content of porridges prepared with unrefined maize together with the addition of dried whole fish consumed with bones has the potential to markedly improve the bioavailability of iron and zinc. By implementing these combined household strategies, the estimated requirements for these two limiting micronutrients can be met. To be successful, however, potential strategies must be economically feasible, culturally acceptable and sustainable, and must not increase the cost, preparation, and cooking time of the meals or the workload of the caregivers. Further, to be effective, these strategies must be integrated with ongoing national agriculture, food, nutrition and health education programs and implemented using a participatory approach to ensure their acceptability, adoption, and sustainability.

\section{Acknowledgments}

This work was supported in part by grants from the Canadian International Development Agency through the Micronutrient Initiative, Opportunities for Micronutrient Interventions (OMNI) Research Program of the United States Agency for International Development (USAID), and the Thrasher Research Fund.

\section{References}

Allen LH (1994) Vitamin B-12 metabolism and status during pregnancy, lactation and infancy. In Nutrient Regulation during Pregnancy, Lactation, and Infant Growth, pp. 173-186 [L Allen, J King and B Lönnerdal, editors]. New York: Plenum Press.

Allen LH \& Ahluwalia N (1997) Improving Iron Status Through Diet. The Application of Knowledge Concerning Dietary Iron Bioavailability in Human Populations, Arlington: John Snow, Inc./OMNI Project.

Bartnik M \& Szafranska I (1987) Change in phytate content and phytase activity during the germination of some cereals Journal of Cereal Science 5, 23-28.

Becker B (1986) Wild plants for human nutrition in the Sahelian zone. Journal of Arid Environments 11, 61-64.

Brummett RE \& Haight B (1996) Research-development linkages. In Report of the Expert Consultation on Small Scale Rural Aquaculture, pp. 145-169, FAO Fisheries Report No. 548. Rome: Food and Agriculture Organization of the United Nations.

Bunch S \& Murphy SP (1997) User's Guide to the Operation of the World Food Dietary Assessment Program. Berkeley, CA: Office of Technology Licensing, University of California.

Camacho L, Sierra C, Campos R, Guzman E \& Marcus D (1992) Nutritional changes caused by germination of legumes commonly eaten in Chile. Archivos Latinoamericanos de Nutricion 42, 283-290.

Chang R, Schwimmer S \& Burr HK (1977) Phytate: removal from whole dry beans by enzymatic hydrolysis and diffusion. Journal of Food Science 42, 1098-1101.

COMA-Committee on Medical Aspects of Food Policy (1991) Dietary Reference Values for Food Energy and Nutrients for the United Kingdom: Report on Health and Social Subjects 41. London: Her Majesty's Stationery Office.

Cook JD \& Monsen ER (1976) Food iron absorption in human subjects. 3 Comparison of the effect of animal proteins on nonheme iron absorption. American Journal of Clinical Nutrition 29, 859-867.

De Boland AR, Garner GB \& O’Dell BL (1975) Identification and properties of phytate in cereal grains and oilseed products. Journal of Agricultural and Food Chemistry 23, 1186-1189.

de Pee, Bloem MW, Satoto, Yip R, Sukaton A, Tjiong R, Shrimpton R, Muhilal \& Kodyat B (1998) Impact of a social marketing campaign promoting dark-green leafy vegetables and eggs in Central Java, Indonesia. International Journal of Vitamin and Nutrition Research 68, 389-398.

FAO/WHO - Food and Agricultural Organization/World Health Organization (1988) Requirements of Vitamin A, Iron, Folate and Vitamin B-12. Rome: FAO.

Ferguson EL, Gibson RS, Thompson LU, Ounpuu S \& Berry M (1988) Phytate, zinc and calcium contents of 30 East African foods and their calculated phytate: $\mathrm{Zn}, \mathrm{Ca}$ : phytate, and $[\mathrm{Ca}][$ phytate $] /[\mathrm{Zn}]$ molar ratios. Journal of Food Composition and Analysis 1, 316-325.

Ferguson EL (1992) A comparison of the seasonal food consumption patterns and zinc status of preschool children living in rural areas of Southern Malawi and Southern Ghana. PhD Thesis, University of Guelph.

Grenier R \& Konietzny U (1999) Improving enzymatic reduction of myo-inositol phosphates with inhibitory effects on mineral absorption in black beans (Phaseolus vulgaris var. preto). Journal of Food Processing and Preservation 23, 249-261.

Gibson RS (1994) Zinc nutrition in developing countries. Nutrition Research Reviews 7, 151-173.

Gibson RS \& Ferguson EL (1998) Nutrition intervention strategies to combat zinc deficiency in developing countries. Nutrition Research Reviews 10, 1-18.

Graham RD \& Welch RM (1996) Breeding for staple food crops with high micronutrient density. Working Papers on Agricultural Strategies for Micronutrients, No. 3. Washington, DC: International Food Policy Research Institute.

Hagenimana V, Oyunga MA, Low J, Gichuki S \& Kabira J (1999) The Effects of Women Farmers' Adoption of Orange-Fleshed Sweet Potatoes: Raising Vitamin A Intake in Kenya. Washington, DC: International Center for Research on Women.

Hallberg L \& Rossander L (1984) Improvement of iron nutrition in developing countries: Comparison of adding meat, soy protein, ascorbic acid, citric acid, and ferrous sulphate on iron absorption from a simple Latin American-type of meal. American Journal of Clinical Nutrition 39, 577-583.

Hansen M, Thilsted SH, Sandström B, Kongsbak K, Larsen T, Jensen M \& Sørensen SS (1998) Calcium absorption from small soft-boned fish. Journal of Trace Elements in Medicine and Biology 12, 148-154.

Hirabayashi M, Matsui T \& Yano H (1998) Fermentation of soybean meal with Aspergillus usamii improves zinc availability in rats. Biological Trace Element Research 61, 227-234.

Holland B, Brown J \& Buss DH (1993) Fish and Fish Products. The Third Supplement to McCance \& Widdowson's The Composition of Foods (5th Edition). The Royal Society of Chemistry and Ministry of Agriculture, Fisheries and Food

House WA, Van Campen DR \& Welch RM (1996) Supplemental sulfur-containing amino acids enhance the bioavailability to rats of zinc in corn kernels. Nutrition Research 16, 225-235.

Huddle J-M (1996) Energy intake, iron and zinc nutriture of pregnant women in rural Southern Malawi. PhD Thesis, University of Guelph.

Iglesias C (1996) Genetic potential and stability of beta-carotene content in Cassava roots. Micronutrients and Agriculture 2, 2 14.

Irving GCJ (1980) Phytase. In Inositol Phosphates. Their Chemistry, Biochemistry and Physiology, pp. 85-98 [DJ Cosgrove, editor]. Amsterdam: Elsevier. 
Kim SH \& Oh S-Y (1996) Cultural and nutritional aspects of traditional Korean diet. World Review of Nutrition and Dietetics 79, 109-132.

Lasztity R \& Lasztity L (1990) Phytic acid in cereal technology. Advances in Cereal Science Technology 10, 309-371.

Lönnerdal B, Sandberg A-S, Sandström B \& Kunz C (1989) Inhibitory effects of phytic acid and other inositol phosphates on zinc and calcium absorption in suckling rats. Journal of Nutrition 119, 211-214.

Lorenz K (1980) Cereal sprouts: composition, nutritive value, food applications. Critical Reviews in Food Science and Nutrition 13, 353-385.

Lynch SR, Hurrell RF, Dassenko SA \& Cook JD (1989) The effect of dietary proteins on iron bioavailability in man. Advances in Experimental Medicine and Biology 248, 117-132.

Maage A \& Julshamn K (1993) Assessment of zinc status in juvenile Atlantic salmon (Salmo salar) by measurement of whole body and tissue levels of zinc. Aquaculture 117, 179191.

Malaisse F \& Parent G (1985) Edible wild vegetable products in the Zambezian woodland area. A nutritional and ecological approach. Ecology of Food and Nutrition 18, 43-82.

Mendoza C, Viteri Fe , Lönnerdal B, Young KA, Raboy V \& Brown KH (1998) Effect of genetically modified low phytic acid maize on absorption of iron from tortillas. American Journal of Clinical Nutrition 68, 1123-1127.

Mølbak K, Jensen H, Ingholt L \& Aaby P (1997) Risk factors for diarrheal disease incidence in early childhood: a community cohort study from Guinea-Bissau. American Journal of Epidemiology 146, 273-282.

Mosha AC \& Svanberg U (1990) The acceptance and intake of bulk-reduced weaning foods: The Luganga village study. Food and Nutrition Bulletin 12, 69-74.

O'Dell BL, de Bowland AR \& Koirtyohann SR (1972) Distribution of phytate and nutritionally important elements among the morphological components of cereal grains. Journal of Agricultural and Food Chemistry 20, 718-721.

Pen J, Verwoerd TC, van Paridon PA, Beudeker RF, van den Elzen PJM, Geerse K, van der Klis JD, Versteegn HAJ, van Ooyen AJJ \& Hoekema A (1993) Phytase-containing transgenic seeds as a novel feed additive for improved phosphorus utilization. Bio/Technology 11, 811-814.

Raboy V, Below FE \& Dickinson DB (1989) Alterations of maize kernel phytic acid levels by recurrent selection for protein and oil. Journal of Heredity 80, 311-315.

Sandberg A-S (1991) The effect of food processing on phytate hydrolysis and availability of iron and zinc. In Nutritional and Toxicological Consequences of Food Processing, pp. 499-508 [M Friedman, editor]. New York: Plenum Press.

Sandberg A-S, Rossander Hulthen L \& Turk M (1996) Dietary Aspergillus niger phytase increases iron absorption in humans. Journal of Nutrition 126, 476-480.

Sandberg A-S, Brune M, Carlsson N-G, Hallberg L, Skoglund E \& Rossander-Hulthen L (1999) Inositol phosphates with different numbers of phosphate groups influence iron absorption in humans. American Journal of Clinical Nutrition 70, 240-246.

Sandström B, Almgren A, Kivisto B \& Cederblad A (1989) Effect of protein and protein source on zinc absorption in humans. Journal of Nutrition 119, 48-53.

Shrimpton R (1995) Community participation in food and nutrition programs: an analysis of recent government experiences. In Child Growth and Nutrition in Developing Countries, pp. 243-261 [P Pinstrup-Anderson, D Pelletier and H Alderman, editors]. Ithaca: Cornell University Press.

Svanberg U, Lorri W \& Sandberg A-S (1993) Lactic fermentation of non-tannin and high-tannin cereals: effects on in vitro estimation of iron availability and phytate hydrolysis. Journal of Food Science 58, 408-412.

United Nations Administrative Committee on Coordination SubCommittee on Nutrition (1997) Third Report of the World Nutrition Situation. Geneva: WHO.

World Health Organization (1983) Measuring change in nutritional status: guidelines for assessing the nutritional impact of supplementary feeding programmes for vulnerable groups. Geneva: WHO.

World Health Organization (1996) Trace elements in human nutrition and health. Geneva: WHO.

World Health Organization (1998) Complementary feeding of young children in developing countries: a review of current scientific knowledge. Geneva: WHO.

Ye X, Al-Babili S, Kloti A, Zhang J, Lucca P, Beyer P \& Potrykus I (2000) Engineering the provitamin A (beta-carotene) biosynthetic pathway into (carotenoid-free) rice endosperm. Science 287, 303-305. 